\title{
PERLINDUNGAN HUKUM TERHADAP PEREMPUAN DAN ANAK YANG MENJADI KORBAN KEKERASAN DALAM RUMAH TANGGA DI DESA KLIS
}

\author{
H. Z. Wadjo ${ }^{1}$, Astuti Nur Fadillah ${ }^{2}$ \\ ${ }^{1,2)}$ Program Studi Ilmu Hukum, Fakultas Hukum, Universitas Pattimura \\ email: dibawadjo123@gmail.com
}

\begin{abstract}
Abstrak
Kekerasan dalam rumah tangga merupakan salah satu bentuk kekerasan yang berdasarkan pada asumsi yang biasa atas gender tentang relasi antara laki-laki dan perempuan. Kekerasan dalam rumah tangga bersumber pada cara pandang yang keliru, yakni martabat kemanusiaan dan pembakuan peran gender pada seseorang itu diremehkan. Kekerasan perempuan tidak hanya dijumpai pada kekerasan fisik semata tetapi kekerasan secara psikis Kekerasan terhadap perempuan dan anak di Desa Klis Kabupaten Maluku Barat Daya termasuk yang cukup memprihatinkan, karena banyak dari mereka yang menjadi korban.Tujuan pengabdian ini dilakukan untuk memberikan informasi kepada masyarakat bahwa perempuan dan anak telah diberi perlindungan terhadap negara melalui peraturan perundang-undangan, salah satunya adalah Undang-undang No. 23 tahun 2004 tentang Penghapusan Kekerasan Dalam Rumah Tangga. Metode yang digunakan pada pengabdian ini adalah memberikan sosialisasi hukum tentang Undang-undang tindak pidana kekerasan dalam rumah tangga dan perlindungan anak dibawah umur. Hasil kegiatan pengabdian ini adalah memberikan pemahaman kepada masyarakat mengenai KDRT. Tujuan dari pengabdian ini agar masyarakat dapat mencegah terjadinya KDRT dimasa yang akan datang.
\end{abstract}

Kata Kunci : Perlindungan Hukum, Kekerasan, Perempuan, dan Anak

\begin{abstract}
Domestic violence is a form of violence based on gender-biased assumptions about the relationship between men and women. Domestic violence originates from a wrong perspective, namely disregarding humanity and the standardization of gender roles in a person is underestimated. Violence against women is not only found in physical violence but psychological violence. Violence against women and children in Klis Village, Southwest Maluku Regency is quite concerning, because many of them have become victims. The purpose of this service is to provide information to the public that women and children have been protected against the state through laws and regulations, one of which is Undang-undang No. 23/2004 concerning the Elimination of Domestic Violence. The method used in this service is to provide legal dissemination on the law on criminal acts of domestic violence and protection of minors. The result of this service activity is to provide understanding to the community about domestic violence. The purpose of this service is so that the community can prevent future domestic violence from occurring.
\end{abstract}

Keywords : Legal Protection, Violance, Women, Children

\section{PENDAHULUAN}

Desa Klis merupakan salah satu desa yang ada di Kecamatan Moa Lakor, kabupaten Maluku Barat Daya. Desa Klis merupakan satu dari 7 desa dan kelurahan yang berada di kecamatan Pulau Damer. Letak Desal Klis berjarak kurang lebih $20 \mathrm{~km}$ dari Tiakur, dengan fasilitas jalan yang masih belum aspal secara keseleuruhan. Budaya yang kental masih dijalankan oleh suku Tanimbar ialah budaya Duan - Lolat. Budaya ini berhubungan dengan status sosial dari hubungan perkawinan, dimana, dalam budaya Duan - Lolat, perkawinan menjadi dasar dalam menentukan status 
sosial calon mempelai. Salah satu permasalahan sosial yang sering terjadi pada desa ini adalah Kekerasan Dalam Rumah Tangga

Kekerasan terhadap perempuan dan anak yang terjadi pada lingkungan masyarakat Indoenesia saat ini menjadi salah satu bentuk masih kurangnya pemahaman pada masyarakat bahwa setiap warna negara di Indoensia berhak mendapatkan rasa aman dan bebas dari segala bentuk kekerasan sesuai dengan falsafah Pancasila dan Undang-Undang Dasar Negara Republik Indonesia Tahun 1945. Dalam masyarakat terdapat pandangan yang menempatkan perempuan rendah, karena dianggap bertentangan dengan kodratnya (menurut kodratnya perempuan makhluk lemah lembut, perasa, sabar, dan lain-lain). (Hehanussa \& Salamor, 2019).

Kekerasan dalam rumah tangga, merupakan pelanggaran hak asasi manusia dan kejahatan terhadap martabat kemanusiaan serta bentuk diskriminasi yang harus dihapus. Pasal 1 ayat 1 pada Undang-undang No, 23 tahun 2004 tentang Penghapusan Kekerasan dalam Rumah Tangga menjelaskan pengertian Kekerasan dalam Rumah Tangga adalah setiap perbuatan terhadap seseorang terutama perempuan, yang berakibat timbulnya kesengsaraan atau penderitaan secara fisik, seksual, psikologis, dan/atau penelantaran rumah tangga termasuk ancaman untuk melakukan perbuatan, pemaksaan, atau perampasan kemerdekaan secara melawan hukum dalam lingkup rumah tangga. Korban kekerasan dalam rumah tangga, yang kebanyakan adalah perempuan dan anak, harus mendapat perlindungan dari negara dan/atau masyarakat agar terhindar dan terbebas dari berbagai macam kekerasan atau ancaman kekerasan, penyiksaan, atau perlakuan yang merendahkan derajat dan martabat kemanusiaan.

Ada banyak jenis-jenis kekerasan dalam rumah tangga diantara lain adalah :

1. Kekerasan fisik : menampar, menempeleng, memukul, membenturkan ke benda lain, dsb, sampai ke bentuk-bentuk kekerasan yang mengancam keselamatan.

2. Kekerasan mental : kata-kata yang menyakitkan, bentakan, penghinaan, ancaman, dan sebagainya

3. Kekerasan ekonomi : larangan bekerja, mengontrol pendapatan istri, tidak memberikan uang yang cukup untuk keluarga

4. Kekerasan seksual : perkosaan, pemaksaan kehamilan, pemukulan atau bentuk penyiksaan lain yang menyertai hubungan intim, pornografi, penghinaan terhadap seksualitas perempuan dengan bahasa verbal. (bentuk kekerasan terhadap perempuan saling berkaitan /tdak berdimensi tunggal)

Tingginya kasus kekerasan dalam rumah tangga memberikan banyak rasa kekhawatiran dimasyarakat. Kekerasan yang terjadi pada perempuan dan anak ini akan mengakibatkan trauma kepada korban. Penyebab kekerasan dalam rumah tangga sangat kompleks dan berkaitan dengan keyakinan bahwa laki-laki memiliki kekuasaan atas perempuan (dan anak), dan bisa memperlakukannya dengan kasar kalau ia menghendaki.

Hak Asasi terhadap perempuan harus mendapat perhatian lebih dari pemerintah mengingat bahwa perempuan sangat rentan menjadi korban dalam lingkup keluarga maupun masyarakat. Ada ketidakcocokan yang nyata antara kerangka hukum dan, kenyataan sehari-hari yang menjadi kekerasan terhadap perempuan sering dianggap sebagai suatu masalah domestik, bersifat pribadi, sehingga boleh diabaikan secara hukum.

\section{METODE}

Kegiatan pengabdian masyarakat yang dilaksanakan di Desa Klis dilakukan dengan menggunakan metode memberikan pemahaman kepada masyarakata berupa sosialisasi hukum tentang Undang-undang tindak pidana kekerasan dalam rumah tangga dan perlindungan anak dibawah umur. Sosialisasi ini sangat diharapkan menjadi wujud bentuk Pengabdian Masyarakat Dosen dan Mahasiswa Fakultas Hukum Universitas Pattimura, dalam memberikan pemahaman kepada masyarakat Desa Klis mengenai perlindungan hukum terhadap perempuan dan anak yang menjadi korban kekerasan pada 
lingkup rumah tangga. Agar masyarakat Desa Klis dapat memahami bagaimana pencegahan agar tidak lagi terjadi kekerasan dimasa yang akan datang.

\section{HASIL DAN PEMBAHASAN}

Kegiatan sosialisasi hukum tentang Undang-undang Tindak Pidana Kekerasan dalam Rumah Tangga dan Perlindungan Anak Dibawah Umur, merupakan salah satu kegiatan yang dilakukan sebagai wujud dalam melaksanakan tridharma perguruan tinggi. Sosialisasi ini dilakukan untuk memberikan pemahaman lebih kepada masayarakat Desa Klis akan adanya paying hukum yang diberikan oleh Pemerintah Indonesia dalam mewujudkan perlindungan terhadap perempuan dan anak di Indonesia.

Dalam lingkup keluarga kekerasan yang terjadi kaitannya dengan status dan peran yang berbeda antara suami dan isteri, sehingga bentuk-bentuk kekerasannya bersifat eksploitasi dan dominasi. Perempuan tidak diberi status dan peran sesuai dengan haknya karena kontrol dalam urusan rumah tangga ada pada suami. Pada kondisi ini suami dengan mudah dapat melakukan kekerasan baik fisik maupun psikologis, karena yang menjadi pedoman tindaka suami adalah kekuasaan (power) (Sulaeman \& S Homzah, 2010). Masyarakat memandang kekerasan yang dialami oleh perempuan dan anak ini masih dianggap sebagai aib keluarga yang harus disembunyikan dari masyarakat luas. Persepsi ini yang terkadang membuat masyarakat menganggap bahwa permasalahan KDRT ini merupakan urusan yang sangat pribadi dan pihak luar (dalam hal pihak keluarga luar, masyarakat dan penegak hukum) tidak patut untuk ikut campur dalam permasalahan tersebut.

Adapun faktor-faktor terjadinya Kekerasan Dalam Rumah Tangga (selanjutnya disebut dengan KDRT) antara lain :

1. Ketimpangan relasi antara laki-laki dan perempuan, membuat lelaki dan perempuan terpaksa mematuhi peran gender yang dilekatkan masyarakat pada mereka. Suami adalah pemimpin (penguasa) dalam keluarga, isteri adalah milik suami dan berada di bawah pengawasannya. Pengontrolan ini sering menggunakan tindak kekerasan

2. Ketergantungan isteri secara penuh kepada suami. Suami menggunakan ketergantungan ekonomi ini sebagai ancaman jika isteri tidak mengikuti apa yang dikehendaki. Ancaman bisa berwujud tindak kekerasan, tidk memberikan nafkah, perceraian, penguasaan hak asuh anak, penguasaan harta bersama.

3. Pengabaian oleh masyarakat, dan keyakinan yang salah satu tentang kodrat termasuk yang berdasar tafsir agama. Masyarakat menganggap KDRT sebagai urusan internal sehingga tidak berhak campur tangan. Isteri yang saleh adalah isteri yang mampu menjaga aib dan martabat keluarga, termasuk tindak kekerasan yang ditimpahkan kepadanya

4. Mitos tentang KDRT. Mitos merupakan cerita dalam suatu kebudayaan yang dianggap sebagai sebuah kebenaran pada masa lalu. Mitos dipercaya oleh masyarakat dan dijadikan rujukan. Pada akhirnya mitos memojokan korban dalam kasus-kasus kekerasan.

Dalam hal perlindungan hak terhadap perempuan diharapkan dengan adanya konvensi dan undang-undang untuk melindungi perempuan dari pelanggaran HAM. Ditinjau dari padanganan Hak Asasi Manusia, perempuan juga harus mendapatkan keadilan dan rasa aman dalam hidup. Karena hukum pada dasarnya harus mencerminkan keadilan yang menjangkau pihak perempuan yang selama ini dianggap sebagai kaum yang lemah yang senantiasa mendapat perlakuan tidak semestinya. Melalui UU No. 23 tahun 2004 tentang Penghapusan KDRT, memperluas definisi KRDT dan korban potensi kekerasan dalam rumah tangga, mengkriminalisasi pelecehan seksual untuk pertama kalinya di Indonesia, dan mengakui hak-hak korban. Hak-hak ini meliputi :

1. perlindungan korban oleh polisi, peradilan, pengadilan, pengacara dan lembaga sosial;

2. pelayanan kesehatan sesuai dengan kebutuhan medis korban, 
3. hak terjaganya kerahasiaan korban;

4. dukungan oleh pekerja sosial dan tersedianya bantuan hukum untuk setiap tahap pemeriksaan; dan

5. pelayanan konseling.

UU PKDRT ditujukan kepada seluruh anggota keluarga tetapi pada khususnya perempuan sebab berdasarkan fakta sebagian besar korban adalah perempuan. Pendampingan dalam proses hukum tidak saja didampingi oleh pengacara tetapi juga oleh ahli lain yang bukan pengacara, bahkan pengacara harus berkoordinasi dengan ahli tersebut.

Selain perempuan, anak juga sering menjadi salah satu korban dari KDRT itu sendiri. Salah satu bentuk kekerasan yang sering dialami oleh anak dan tanpa disadari oleh orang tua adalah kekerasan verbal. Kekerasan verbal adalah kekerasan yang dilakukan secara lisan yang dilakukan secara terus menerus hingga menyebabkan terhambatnya perkembangan pada anak usia dini. Beberapa bentuk kekerasan verbal yang sering terjadi pada anak diantaranya mengancam, memfitnah, menghina, membesar-besarkan kesalahan yang dilakukan oleh anak, dan sebagainya. Jika anak mendapatkan kekerasan verbal secara terus menerus, maka akan menyebabkan terhambatnya perkembangan anak. Anak akan merasa terkucilkan, merasa tidak dibutuhkan, hingga membuat anak menjadi rendah diri. Hal ini tentunya akan berpengaruh pada aspek perkembangan yang lain (Mahmud, 2019).

Pemerintah, masyarakat, keluarga, dan orang tua berkewajiban dan bertanggungjawab terhadap penyelenggaraan perlindungan anak Perlindungan anak bertujuan untuk menjamin terpenuhinya hak-hak anak, agar dapat hidup, tumbuh, berkembang, dan berpartisipasi secara optimal, sesuai dengan harkat dan martabat kemanusiaan, serta mendapat perlindungan dari kekerasan dan diskriminasi demi terwujudnya anak Indonesia yang berkualitas, berakhlak mulia, dan sejahtera. Pemerintah, masyarakat, keluarga, dan orang tua berkewajiban dan bertanggungjawab terhadap penyelenggaraan perlindungan anak.

Penyelesaian kasus terhadap kekerasan pada perempuan dan anak yang sering manjadi kendala adalah masih ada perspektif dari masyarakat jika itu merupakan urusan lingkup rumah tangga, dimana orang lain tidak ingin ikut campur dalam permasalahan kasus ini. Padahal KDRT merupakan wilayah public dan jika terjadi KDRT aparat dan masyarakat berhak masuk dalam wilayah yang selam ini disebut rana privat.

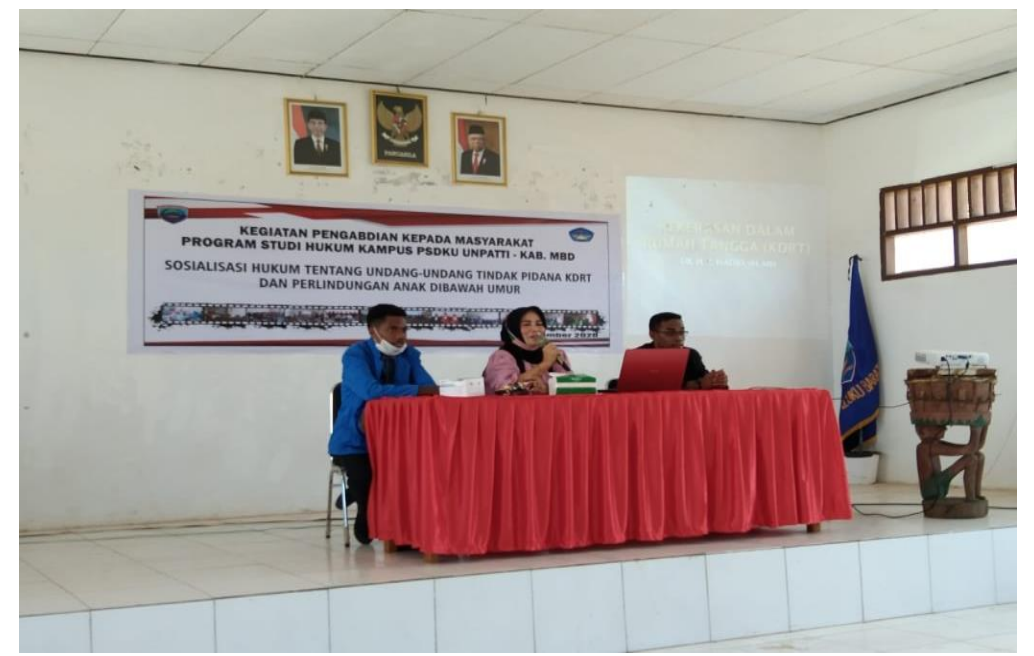

Gambar 1.1 Pemaparan materi oleh pemateri

Kegiatan sosialisasi ini dibuka oleh moderator yang kemudian bertindak dalam memandu proses dari sosialisasi ini. Kemudian moderator kemudian memberikan pengantar mengenai ruang lingkup KDRT itu sendiri, kemudian moderator menyerahkan kepada dosen fakultas hukum Universitas Pattimura dalam memberikan materi sosialisasi 
mengenai KDRT di Desa Klis ini. Setelah pemaparan materi telah dilakukan, pemateri mengajak diskusi masyarakat mengenai KDRT ini. Hasil diskusi dengan masyarakat ini menemukan fakta baru bahwa penyelesaian kasus kekerasan terhadap perempuan dan anak di Desa Klis biasanya diselesaikan dalam proses adat sehingga tidak memberikan efek jera kepada para pelaku kekerasan ini.

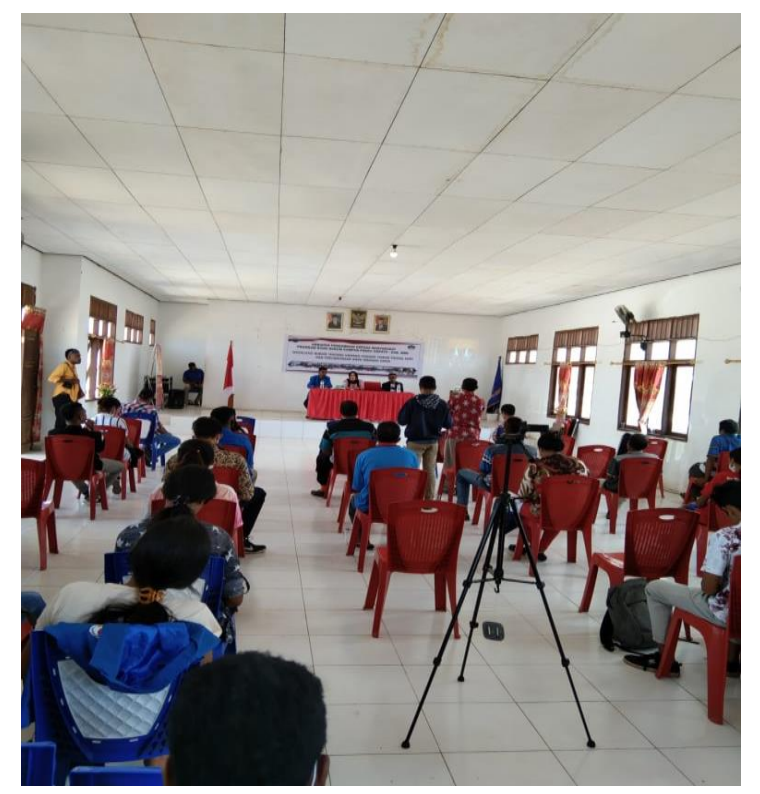

Gambar 1.2 Proses berjalanya diskusi dengan masyarakat Desa Klis

Setelah proses pemberian sosialisasi dan diskusi dengan masyarakat mengenai KDRT di Desa Klis ini diharapkan menambah pemahaman pada masyarakat akan bahaya dari kekerasan tersebut.

\section{SIMPULAN}

Perlindungan hukum terhadap perempuan dan anak yang menjadi korban kekerasan dalam rumah tangga perlu menjadi perhatian semua pihak. Perempuan dan Anak memiliki hak yang sama yang harus dilindungi bersama.

\section{UCAPAN TERIMA KASIH}

Pemerintahan Desa Klis

Masyarakat Desa KLis

Program Studi Hukum Kampus PSDKU MBD

Fakultas Hukum Universitas Pattimura

\section{DAFTAR PUSTAKA}

Hehanussa, D. J. A., \& Salamor, Y. B. (2019). Membangun kesadaran hukum perempuan dan anak seksual. Sabdamas, 1(1), 292-297.

Mahmud, B. (2019). Kekerasan verbal pada anak. Jurnal An Nisa', 12(2), 689-694.

Sulaeman, M., \& S Homzah. (2010). Kekerasan Terhadap Perempuan Tinjauan dalam Berbagai Disiplin Imu dan Kasus Kekerasan. Refika Aditama. 